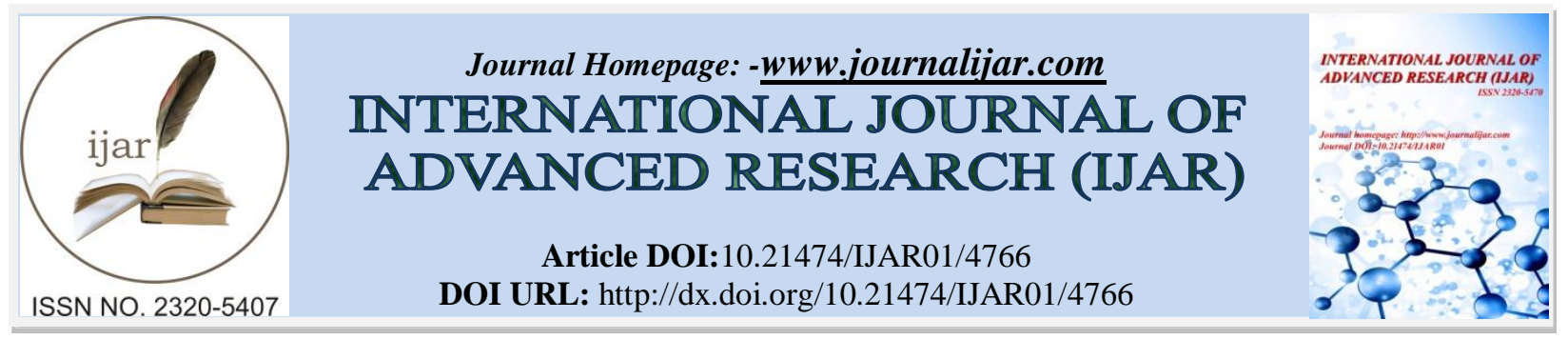

RESEARCH ARTICLE

\title{
EFFECT OF NATURAL RESOURCES ON REPRODUCTIVE HEALTH AND OXIDATIVE STRESS OF FEMALE CONSTRUCTION WORKERS, WEST BENGAL, INDIA.
}

\author{
Sugata Das ${ }^{1}$, Dr.Anandi Bagchi ${ }^{2}$, Prof Somnath Gangopadhyay ${ }^{3}$ and Dr.Subrata Ghosh ${ }^{4}$. \\ 1. Research Scholar, Department of Physiology, University of Calcutta. \\ 2. Assistant Professor, Department of Physiology, Jhargram Raj College (Girls' Wing), Govt. of West Bengal. \\ 3. Professor, Department of Physiology, University of Calcutta. \\ 4. Associate Professor, Department of Physiology, Hooghly Mohsin College. Govt. of West Bengal.
}

\section{Manuscript Info}

\section{Manuscript History}

Received: 7 May 2017

Final Accepted: 9 June 2017

Published: July 2017

Key words:-

oxidative stress, glutathione, $25 \mathrm{OH}$ Vitamin D, progesterone, estrogen, natural resources, construction workers.

\section{Abstract}

Background: Modernization and industrialization have paved a good path to the construction industry. As per Census 2011, the total number of female workers in India is 149.8 million.

Objectives: To identify different health problems amongst workers working in the construction industry in West Bengal, to assess health status of these female construction workers with respect to their occupational hazards and hormonal dysfunctions and recommend some low cost easily available supplement in controlling or preventing these potentially damaging reactions of these construction female workers.

Materials and Methods: The study was a double-blind study with intervention conducted in different construction sites of Howrah, Hooghly, and 24 parganas of West Bengal amongst 123 female construction workers. All general physical parameters, reproductive hormonal parameters, oxidative stress parameter, $25 \mathrm{OH}$ Vitamin D were performed in pre and post intervention condition by standardised procedure. Workers were asked to take antioxidant multivitamin capsule (Lycopene), raw turmeric and one piece of raw garlic in the morning in empty stomach and tomatoes, spinach and onions were included in their daily food.

Result: Workers showed raised Vit D, GSH, progesterone-estrogen ratio, cortisol status $(\mathrm{p}<0.05)$ after1 month intervention study.

Conclusion: Due to stressful job routine, female construction workers faced abnormal level of reproductive hormone and oxidative stress hormonal parameters. Use of multivitamin capsule, raw turmeric, raw garlic, green leafy food, tomatoes, spinach etc balances all hormonal levels moderately

Copy Right, IJAR, 2017,. All rights reserved.

\section{Introduction:-}

Modernization and industrialization have paved a good path to the construction industry. It is one of the important industries employing a large number of people on its workforce. There are more than 20 million construction workers in India at present. India's economy is based on Agriculture, Industry, and Services. In India, the construction industry is the second largest and a fast growing sector. A wide range of activities are involved in it. Due to the advent of industrialization and recent developments, this industry is taking a pivotal role for construction of a nation. The workers

Corresponding Author: - Dr. Subrata Ghosh,

Address:- Associate Professor, Department of Physiology, Hooghly Mohsin College, Chinsurah.

Hooghly, West Bengal, India. 
engaged in this industry are victims of different occupational disorders and psychosocial stresses. In India, though construction labors belong to both organized and unorganized sectors, yet mostly they are unorganized. Construction industry provides job opportunity to large number of skilled as well as unskilled workforce. The workforces employed in the industry have to face several difficulties related to health, job stress, and injuries at the work place. However, data in respect to occupational health and psychosocial stress are scanty in our country.

Women work as unskilled labour in construction industry and face several other difficulties in comparison to males. Sexual harassment, gender bias, wage discrimination, unhealthy job relationship, lower pay etc are the major factors due to which the working environment becomes difficult in the industry and women experience same level of stress factors, in spite of better skilled production after working for a number of years. In India, women-workers constitute about one-fifth of the total work force in the overall economic activity. ${ }^{[1]}$

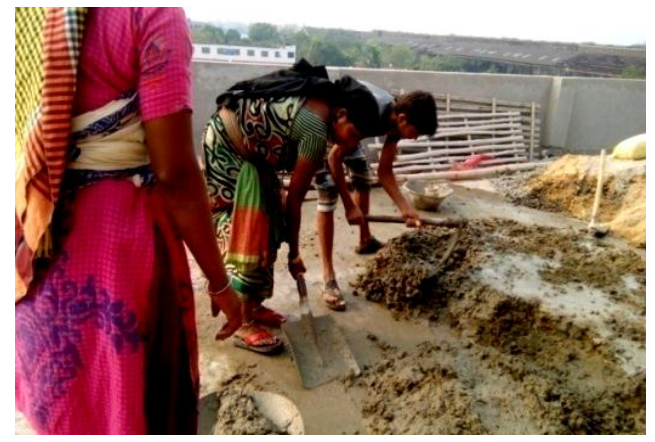

According to the National Sample Survey conducted by NSSO in 2009-2010, about 4.4 crore workers are employed in the construction industry. As per Census 2011, the total number of female workers in India is 149.8 million comprising of 121.8 and 28.0 million in rural and urban areas respectively. Out of total 149.8 million female workers, 35.9 million females are working as cultivators and another 61.5 million are agricultural laborers. 8.5 million females are in household industry. Of the remaining, most of the females are working in construction industry. As per Census 2011, the work participation rate for women is $25.51 \%$ as compared to $25.63 \%$ in 2001. The work participation rate for women in rural areas is $30.02 \%$ as compared to $15.44 \%$ in the urban areas. ${ }^{[2]}$

Around $16 \%$ of the India's working population depend on building construction for its livelihood and the Indian construction industry today employs about 31million people and creates assets worth over Rs. 200,000 million annually. However, the construction industry in India is facing a huge shortage of manpower. The strength of skilled workforce in construction has dwindled substantially from $15.34 \%$ in 1995 to $10.57 \%$ in 2005 , whereas relative proportions of unskilled workers have gone up from $73.08 \%$ in 1995 to $82.45 \%$ in 2005 . [3]

Female fertility declines with age. The gradual loss of fertility becomes more notable after age $35 y e a r s$ and ends in menopause at a mean age of 45 years. The ovary exhibits an accelerated rate of aging compared with other body systems and it demonstrates a gradual deterioration in the quantity and quality of its follicles ${ }^{[4]}$ Cells have developed a wide range of antioxidant systems to limit production of Reactive oxygen species (ROS), inactivate them and repair cell damage ${ }^{[5][11]}$. Oxidative stress influences the entire reproductive span of women's life. It has been suggested that the age-related decline in fertility is modulated by oxidative stress. ${ }^{[6]}$.

But here the construction female workers had mean age 31years. Oxidative stress may elevate during strenuous physical activity, due to a 10- to 15-fold increase in oxygen consumption to meet energy demands. The cellular antioxidant defense system of the body may be expanded by dietary supplementation of antioxidant. Supplementation may reduce oxidative stress; improve reproductive health, decrease short-term tissue damage and long-term health risks associated with oxidative stress. ${ }^{[7]}$.

Vit D has been used etiologically for the management of PCOS. Since Vit D deficiency is common amongst women suffering from PCOS and having serum concentration of $25 \mathrm{OH}$ Vit D $<20 \mathrm{ng} / \mathrm{ml}$, Vit D deficiency is considered to be a neo-biomarker/ symptom of PCOS.

However, low Vit D status is generally associated with insulin resistance, ovarian /menstrual irregularities, lower pregnancy success, hyperandrogenism, and obesity and elevated cardio vascular risk factor. But in our earlier study, it 
was repeatedly found amongst these poorest of poor female construction workers that these labors are generally suffering from ovarian and menstrual irregularities with lower pregnancy success ${ }^{[8]}$.

Under the circumstances, the study aims to fulfill the following purposes

- To identify different health problems amongst workers working in the construction industry in West Bengal.

- To assess health status of these female construction workers with respect to their occupational hazards and hormonal dysfunctions.

- To recommend some low cost easily available supplement in controlling or preventing these potentially damaging reactions of these construction female workers.

\section{Materials and Methods:-}

The study was a double-blind study with intervention conducted in different construction sites of Howrah, Hooghly and 24 Pgs, West Bengal, India amongst female construction workers.

Study Sample: - The female workers were randomly selected for the study. Thus the sample comprised of 123 females workers from the different construction sites of West Bengal, India. This study was performed following the ethical guidelines for biomedical research on human participants as directed by ICMR, Govt. of India and due permission was taken from the Institutional Ethical Committee (IEC) for research on human participant - of Hooghly Mohsin College, Govt. of West Bengal.

The inclusion criteria were

- Uninterrupted work experience minimum 5 years.

- Not taking any type of regular medicine.

- $\quad$ Subjects age range from 25 to 38 years.

\section{Research design:-}

1. The height $\&$ weight of all subjects were measured by means of anthropometer $\&$ weighing machine.

2. The Body Mass Index (BMI) \&Ponderal Index (PI) of all subjects were calculated by standard formula. BMI was used to measure the degree of adiposity and PI was used for degree of growth restriction.

3. Serum Progesterone, Estrogen and Cortisol level were measured before and after supplementation, by specific ELISA methods to find the effect of work stress on menstrual cycle, which could be a marker of adverse reproductive health.

4. Plasma glutathione level (GSH) was measured by specific HPLC method before and after supplementation, to assess the cellular oxidative stress. Deficiency is increasingly recognized as a risk factor in coronary artery disease, asthma, neurodegenerative disorders, cognitive-behavioral problems, and various types of cancer.

5. Serum 25 hydroxy-vitamin $\mathrm{D}(25 \mathrm{OH}$ Vit $\mathrm{D})$ was measured by specific HPLC method before and after supplementation, to dig up the dramatic effect of vitamin D deficiency on PCOS.

\section{Data collection periods:-}

Data were collected at two time periods.

Period 1: Structured schedule cum measurement technique was adopted to elicit the information about physical parameters and blood samples were collected, in presence of physician.

Diet:-The female construction workers were asked to take raw turmeric and one piece of raw garlic every morning (empty stomach). Workers were also asked to include following vegetables in their daily food habit- tomatoes (raw and cooked), spinach and onions (raw and cooked) for 1 month tenure.

In addition to, intake of one antioxidant multivitamin capsule (Provided) (Androgardian from Cipla, Protec) [Lycopene] every day for one month was advised by the team physician. The composition of the supplement is : Ascorbic acid $295 \mathrm{mg}$, green tea extract $250 \mathrm{mg}$, DL-methionine $50 \mathrm{mg}$, vitamin E acetate $19.46 \mathrm{mg}$, choline $10 \mathrm{mg}$, lycopene $6 \mathrm{mg}$, folic acid $750 \mathrm{mcg}$, selenium $50 \mathrm{mcg}$, protein $0.035 \mathrm{~g}$, carbohydrate $0.055 \mathrm{~g}$, cyanocobalamin $20 \mathrm{mcg}, 5$ tabs of Lcarnitine $500 \mathrm{mg}$, zinc $15 \mathrm{mg}$, protein $0.27 \mathrm{~g}$.

Period 2: After 1 month of supplementation, blood samples were collected. 


\section{Statistical Analysis:-}

Statistical analyses were performed using Minitab 16, 2015. Quantitative variables were expressed as mean \pm SD. Paired $t$ tests were performed to evaluate the overall cumulative oxidative stress when treatment effects were significant. The Pearson correlation coefficient was measured to evaluate the strength of the linear relationship between mentioned variables. $p$-values $<0.05$ were considered to be significant.

\section{Results:-}

The module of supplemental regimen was continued for 1 month from Jan 2017. Our research team volunteered this intervention properly. Blood samples were collected before and after supplementation. Student's t-test indicated significantly raised values of Vitamin D, GSH, Progesterone/Estrogen Ratio, serum cortisol level after intervention study. The positive Pearson correlation means there is a positive relationship between two variables; as one variable increases or decreases, the other tends to increase or decrease with it. Physical parameters are tabulated in Table no 1. Vitamin D, Reproductive hormone and oxidative stress markers in pre and post intervention are represented in Table no 2. Pearson correlations with p-values are expressed in Table no 3.

Table no-1:-Demographic presentation of physical parameters of construction female workers.

\begin{tabular}{|c|c|c|c|}
\hline Variables & Mean values & SD values & SE values \\
\hline Height & 151.10 & 3.20 & 0.211 \\
\hline Weight & 47.048 & 4.848 & 0.320 \\
\hline BMI & 20.577 & 1.717 & 0.113 \\
\hline PI & 13.617 & 1.084 & 0.0715 \\
\hline
\end{tabular}

Table no-2:-Representation of Pre \& Post intervention data of Reproductive hormone, 25OH Vitamin D and oxidative stress marker parameters.

\begin{tabular}{|c|c|c|c|}
\hline Parameter & $\begin{array}{c}\text { Pre intervention } \\
(\text { mean } \pm \text { SD) }\end{array}$ & $\begin{array}{c}\text { Post intervention } \\
(\text { mean } \pm \text { SD })\end{array}$ & p- value $(<\mathbf{0 . 0 5 )}$ \\
\hline Vitamin D & $10.79 \pm 1.024$ & $31.1 \pm 4.19$ & $\mathbf{0 . 0 5 0} *$ \\
\hline P/E ratio & $122.6 \pm 16.24$ & $126.9 \pm 14.01$ & $\mathbf{0 . 0 3 7}^{*}$ \\
\hline GSH & $0.2045 \pm 0.094$ & $0.4533 \pm 0.064$ & $\mathbf{0 . 0 0 0} *$ \\
\hline Cortisol & $7.99 \pm 0.365$ & $10.12 \pm 0.375$ & $\mathbf{0 . 0 0 0} *$ \\
\hline
\end{tabular}

Table no 3:-Representation of correlation with Pre \& Post intervention data of Reproductive hormone, 25OH Vitamin $\mathrm{D}$ and GSH.

\begin{tabular}{|c|c|c|c|c|}
\hline \multirow{2}{*}{ Correlation } & \multicolumn{2}{|c|}{ Pre intervention } & \multicolumn{2}{c|}{ Post intervention } \\
\cline { 2 - 5 } & $\begin{array}{c}\text { Pearson } \\
\text { correlation }\end{array}$ & p-value $(<\mathbf{0 . 0 5})$ & $\begin{array}{c}\text { Pearson } \\
\text { correlation }\end{array}$ & p-value (<0.05) \\
\hline Vit D, P/E ratio & 0.053 & 0.0236 & 0.057 & 0.011 \\
\hline Vit D, Cortisol & 0.069 & 0.018 & 0.307 & 0.018 \\
\hline GSH, P/E ratio & 0.325 & 0.012 & 0.059 & 0.048 \\
\hline GSH, Cortisol & 0.161 & 0.049 & 0.391 & 0.038 \\
\hline
\end{tabular}


Figure legends: Bar diagrams represents pre and post intervention data of Vitamin D, P/E Ratio, Glutathione and Cortisol.
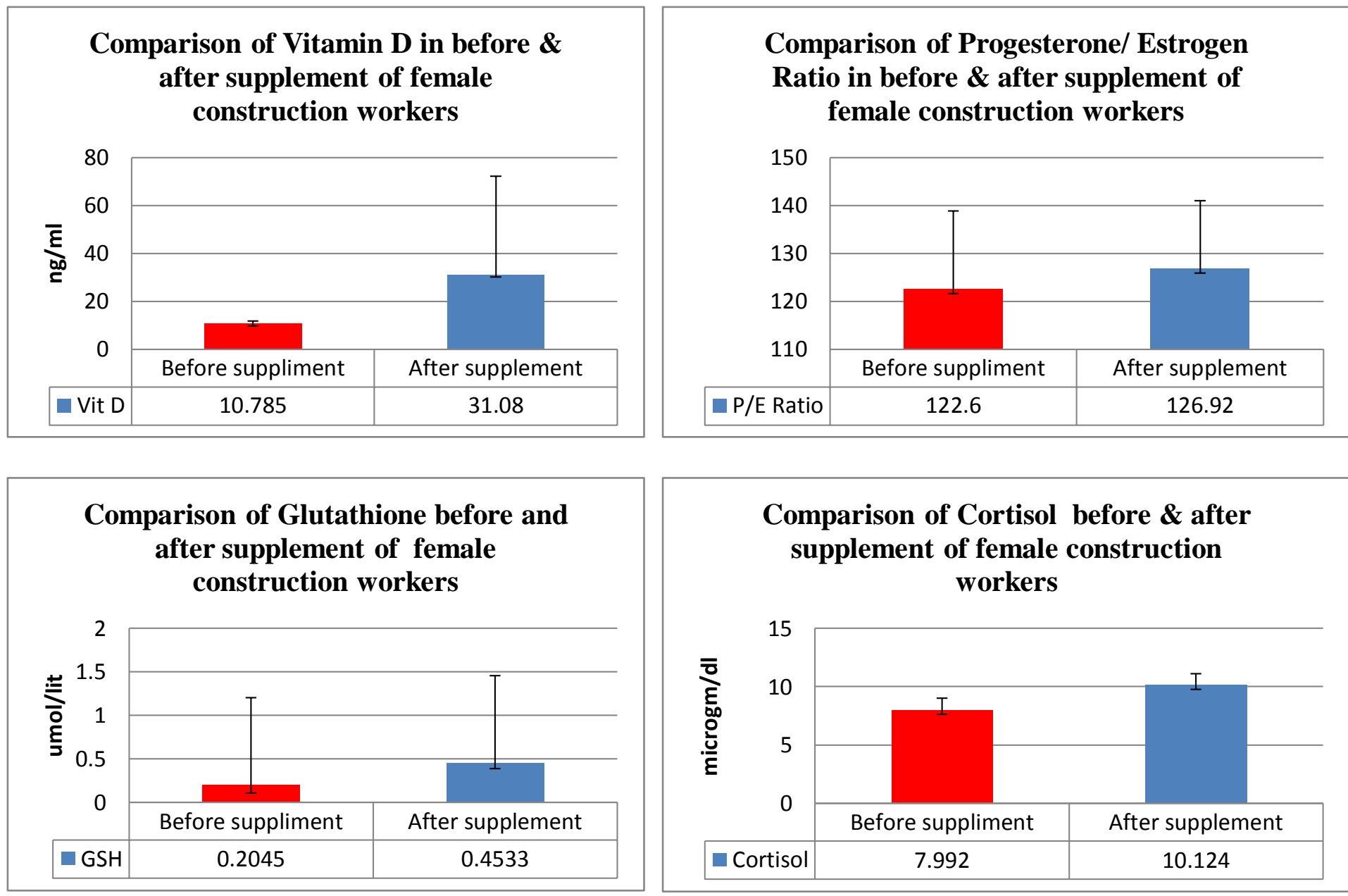

\section{Discussion:-}

The present study investigated stress factors and resulting impact amongst construction female workers. Construction field-work, like other unorganized sectors, is saturated with many occupational health hazards. These female construction workers (subjects) belong to low socioeconomic status. They are daily wage earners. Laborers are compelled to accept extremely strenuous job for their livelihood. The job of the construction workers include cement molding, brick carrying, heavy object lifting, cement carrying, bags of cement and silica carrying. Each sector of these job profiles is found to include additional burden amongst female laborers for obvious reasons.

About $19 \%$ of the construction workers in the urban area and $38 \%$ in the rural area were not eligible for paid leave. It was found that the workers had to work 10-12 hours daily. Very often it happened that they worked day and night to finish a particular construction due to time constraint. The rigorous work led to many diseases and hazards. They fell sick and were not paid for sick leave. The tasks of the cement molders are completed within a cycle time of $10 \pm 5$ minutes. Thus they are bound to complete about 6 such cycles in an hour. Accordingly, female workers had to carry the load at a fast pace, 10 to 12 bricks at a time to compliment the concerned job. They are paid at the rate per thousand bricks carried. So even if they get exhausted, no rest is given in between; i.e. no work-rest pattern was followed: they continued to carry on with their task with heavier strain and pain, which further put the brick carriers under severe stress. This particular study results hereby highlight some of these important situations.

Stress is almost always involved in pre menopausal syndrome (PMS). Stress increases cortisol levels, which blocks binding of progesterone to its receptors. Extra progesterone is necessary to overcome the blockage of its receptors by cortisol. Theoretically, symptoms could relate either to elevated progesterone levels or progesterone deficiency 
(estrogen dominance). Progesterone deficiency (estrogen dominance) is much more likely since many of the symptoms correlate with estrogen dominance symptoms, most notably water retention, breast swelling, headaches, mood swings, loss of libido, and poor sleep patterns. The results of the study present similarity amongst the construction female workers, ensuring the impact of cumulative stress factors in altering the steroid hormonal status in a typical way. [9]

The study outcome significantly noticed that Progesterone: Estrogen Ratio (P/E ratio) is much lower in the subjects concerned. This observation may be treated as biomarker for polycystic ovarian syndrome (PCOS) amongst these subjects. Physicians seriously examined the subjects from clinical point of views. Considering all the symptoms like pain, menstrual record, gap period between consecutive menstruation cycles, duration of periods etc, it was decided to examine their existing Vitamin D status in the serum. By the specific HPLC method it was surprisingly noticed that almost all the subjects were suffering from significant vitamin D deficiency in serum. However, supplementation of antioxidant multivitamin capsule for 1 month significantly elevated their vitamin D level.

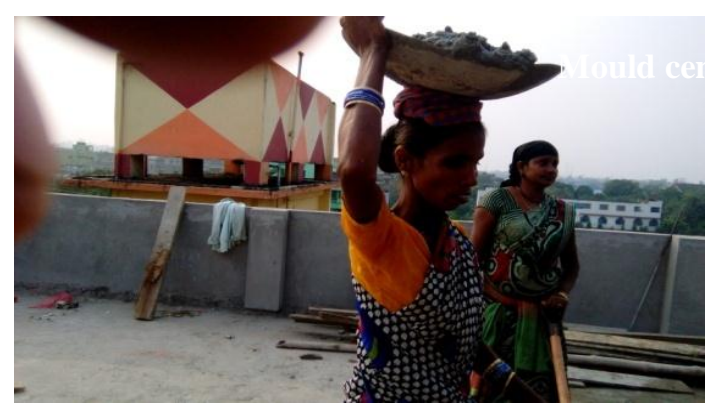

Oxidation happens under a number of circumstances including conditions when our bodies detoxify dust, any type of smoke, pollutants also cellular oxidation increases when we are physically and /or emotionally stressed. The female construction workers studied were exposed to stress maximally. Increasing the antioxidants like glutathione (GSH) in their body system could be one way of mitigating this oxidative stress. Research indicates that herbal sources like raw turmeric, raw garlic, spinach, onion, tomatoes that contain more antioxidant and high sulphur increase GSH level in our body. Construction female workers took such herbal supplement as per recommendation and GSH level significantly increased after one month intervention.

The importance of vitamin D in female reproduction was initially appreciated in vivo. Deficiency in vitamin D leads to an inability to form normal mature eggs, which in turn leads to abnormal reproductive hormonal level and ultimately infertility ${ }^{[10]}$. Initially, the construction female workers showed a low level of serum 25OH Vitamin D. After supplementation of antioxidant multivitamin capsule they showed a significant rise in the progesterone: estrogen ratio and Vitamin D level in serum. Vitamin D also increases antioxidant in body, as is reflected by an increased GSH level in blood of our study group.

Oxidative stress is caused by an imbalance between pro-oxidants and antioxidants. This ratio can be altered by increased levels of reactive oxygen species (ROS). Excessive ROS production, however, may overpower the body's natural antioxidant defense system, creating an environment unsuitable for normal female physiological reactions. This, in turn, can lead to a number of reproductive diseases including endometriosis, polycystic ovary syndrome (PCOS), and unexplained infertility. So, supplementation of antioxidant rich herbal sources along with multivitamin antioxidant capsule also increases progesterone, estrogen, cortisol level significantly. ${ }^{[11]}$

\section{Conclusion:-}

From this study it can be concluded that construction female workers continuously work with stress physically and emotionally. This over-stress hampered their physiological homeostasis affecting their reproductive life, as reflected by their hormonal dysfunctions, low level of $25 \mathrm{OH}$ Vitamin D and Glutathione in blood serum. Quantitative analyses of such hormonal abnormalities amongst female construction workers are the key features of the study. However oral supplementation of multivitamins along with dietary antioxidants could be effective in ameliorating such stress. Furthermore, the study claims that vitamin D deficiency could be an early neo-marker of the reproductive ill-health of these female construction workers. 


\section{Acknowledgement:-}

We are indebted to and convey our deepest sense of gratitude and sincere appreciation to all the female workers of construction sites, Howrah, Hooghly, 24 PGS West Bengal, India and employers for their cooperation and help.

\section{References:-}

1. Tiwary G, Gangopadhyay PK, "A review on the occupational health and social security of unorganized workers in the construction industry". Indian J Occup Environ Med. 2011 Jan; 15(1):18-24.

2. Government of India ministry of labour and employment labour bureau shimla/Chandigarh, "Indian labour year book 2013 and 2014" 2016, Apr; 1-239.

3. Kalpanadevi\&U.V.Kiran, "Status of Female Workers in Construction Industry in India: A Review,IOSR Journal Of Humanities And Social Science.2013 Oct; 14(4): 27-30.

4. Liangyan Shi, Jinjin Zhang, Zhiwen Lai , Yong Tian, Li Fang, Meng Wu, JiaqiangXiong, Xian Qin, AiyueLuo, Shixuan Wang, "Long-Term Moderate Oxidative Stress Decreased Ovarian Reproductive Function by Reducing Follicle Quality and Progesterone Production". PLOS ONE. 2016 Sep; 1-18.

5. Ashok Agarwal, Sajal Gupta and Rakesh K Sharma, "Role of oxidative stress in female reproduction", Reproductive Biology and Endocrinology, BioMEd Central. 2005 July; 1-28.

6. de Bruin JP, Dorland M, Spek ER, Posthuma G, van Haaften M, Looman CW, teVelde ER. Ultrastructure of the resting ovarian follicle pool in healthy young women. BiolReprod. 2002 Apr;66:1151-1160.

7. Wei-Hsun Chao, Eldon W. Askew,3 Donald E. Roberts,Steven M. Wood $\dagger$ and James B. Perkins, "Oxidative Stress in Humans during Work at Moderate Altitude", The Journal of Nutrition.1999 July:2009-2012.

8. Rebecca L. Thomson; Simon Spedding; Jonathan D. Buckley, "Vitamin D in the Aetiology and Management of Polycystic Ovary Syndrome, Clin Endocrinology: 2012;77(3):343-350.

9. Anandi Bagchi, Sugata Das, SougataKarmakar, SubrataGhosh, "Occupational \& ergonomic health analyses of female construction workers of West Bengal, India.", International Journal of Analytical, Pharmaceutical and Biomedical Sciences. 2014 June: 3(2), 55-62.

10. HebaElhusseini, DariaLizneva, Larisa Gavrilova-Jordan, NouraEziba, Mohamed Abdelaziz, SoumiaBrakta, Sunil Halder and Ayman Al-Hendy, "Vitamin D and Female Reproduction", Intech, book publisher: 2017;297-321.

11. Ashok Agarwal, Sajal Gupta and Rakesh K Sharma, "Role of oxidative stress in female reproduction", Reproductive Biology and Endocrinology, BioMEd Central. 2005 July; 1-28. 